\title{
Prevalence of asthma and allergies in children from the Greek-Cypriot and Turkish-Cypriot communities in Cyprus: a bi-communal cross-sectional study
}

Demetris Lamnisos ${ }^{1,2}$, Maria Moustaki ${ }^{3}$, Ourania Kolokotroni ${ }^{1}$, Huseyin Koksoy ${ }^{4}$, Muharrem Faiz ${ }^{5}$, Kenan Arifoglu ${ }^{4}$, Donald K Milton ${ }^{6,7}$, Nicos Middleton ${ }^{2}$ and Panayiotis K Yiallouros ${ }^{1^{*}}$

\begin{abstract}
Background: The Greek-Cypriot (G/C) and Turkish-Cypriot (T/C) communities have lived apart since 1974, with the former presumably adopting a more westernized way of life. We estimated the prevalence of asthma and allergies among children in the two communities and investigated differences in socio-demographic and lifestyle risk factors.

Methods: The ISAAC questionnaire was completed by 10156 children aged 7-8 and 13-14 years. Relative differences in asthma and allergic symptoms between the two communities were expressed as odds ratios (OR), estimated in multivariable logistic regression models before and after adjusting for participants' risk characteristics.

Results: In contrast to our original speculation, consistently lower prevalence rates were observed for respiratory outcomes (but not eczema) among $\mathrm{G} / \mathrm{C}$ compared to $\mathrm{T} / \mathrm{C}$ children in both age-groups. For instance, the prevalence of current wheeze among $7-8$ year-olds was $8.7 \%$ vs $11.4 \%(\mathrm{OR}=0.74,95 \%, \mathrm{Cl}: 0.61,0.90)$ and of current rhinoconjuctivitis $2.6 \%$ vs $4.9 \%(\mathrm{OR}=0.52,95 \% \mathrm{Cl}: 0.37,0.71)$. Surprisingly, the proportion reporting family history of allergy was almost double in the $\mathrm{G} / \mathrm{C}$ community. With the exception of early life nursery attendance, several protective factors were more prevalent amongst T/C, such as bedroom sharing, less urbanized environment and exposure to farm animals. In contrast, exposure to tobacco smoke was more frequent in the T/C community. Controlling for risk factors did not account for the observed lower prevalence of current wheeze (in the younger age-group) and rhinoconjuctivitis (in both age-groups) among $\mathrm{G} / \mathrm{C}$ children while differences in the prevalence of eczema between the two communities were no longer statistically significant.

Conclusions: A mixed picture of potential risk factors was observed in the two communities of Cyprus, not consistently favoring one over the other community since, for example, bedroom sharing and rural living but also exposure to tobacco smoke were more common among $\mathrm{T} / \mathrm{C}$ children. Investigated risk factors do not fully account for the lower prevalence of asthma and allergies among G/C children, especially against a background of higher family history of allergy in this community.
\end{abstract}

Keywords: Asthma, Allergic rhinoconjuctivits, Eczema, Children, Cyprus, Greek Cypriot, Turkish Cypriot

\footnotetext{
*Correspondence: p.yiallouros@cut.ac.cy

${ }^{1}$ Cyprus International Institute for Environmental \& Public Health in

Association with Harvard School of Public Health, Cyprus University of

Technology, Limassol, Cyprus

Full list of author information is available at the end of the article
} 


\section{Background}

Fifteen years ago, the ISAAC phase I study revealed a striking 20-fold international difference in the prevalence of asthma, eczema and rhinoconjuctivitis symptoms [1]. When phase III of the ISAAC study re-assessed five years later the prevalence of the same conditions, the magnitude of observed differences, even though reduced, still remained wide [2,3]. It is now widely accepted that environmental exposures associated with westernized lifestyle are critically implicated in the development of allergic symptoms $[4,5]$. The fact that immigrants to more affluent countries initially have an innate advantage for allergic diseases, which nevertheless attenuates in the next generations can be interpreted in this context [6-8]. Furthermore, genetically similar populations exposed to different environmental conditions display different temporal trends in the prevalence of allergic symptoms. The most characteristic example is that of West and East Germany before unification. Compared to the 150\% increase recorded in West Germany over the preunification period, the increase in East Germany during the same period was only marginal. The difference gradually narrowed after re-unification [9-11].

An interesting paradigm is encountered on the island of Cyprus, where the Greek-Cypriot $(\mathrm{G} / \mathrm{C})$ and TurkishCypriot (T/C) communities have been living apart since 1974, with the former having a higher average income per capita and presumably adopting a more "westernized" way of life. In the G/C community, childhood allergic diseases were recently reported to be rising [12]. Data from the $\mathrm{T} / \mathrm{C}$ community are limited to a single epidemiological study published more than 10 years ago [13]. Despite sharing a small island of $9250 \mathrm{~km}^{2}$, the extent to which potential differences in socio-demographic and lifestyle factors between the two communities may have contributed to a different pattern in terms of childhood allergic conditions epidemiology is largely unknown.

The aim of this study was to provide the first bicommunal study using standardized methodology in order to (a) investigate the prevalence of asthma and allergy symptoms on both sides of the division line in Cyprus and (b) explore the extent to which differences in socio-demographic and other risk characteristics explain any observed differences between the two communities.

\section{Methods}

\section{Study population and design}

Children aged 7-8 and 13-14 years in both communities were contacted at the school setting during 2007-2009. In order to retain comparability with previous studies in the G/C community, schools in two out of the four districts controlled by the Republic of Cyprus (i.e. Nicosia and
Limassol) were invited to participate ( $\mathrm{n}=124,98 \%$ of those contacted) [12]. In the $\mathrm{T} / \mathrm{C}$ community, schools from the whole geographical area north of the division line were invited to participate $(\mathrm{n}=105,100 \%$ of those contacted). Trained field workers in both communities distributed the respective approved Greek and Turkish version of the International Study of Asthma and Allergy in Childhood (ISAAC) core questionnaire, supplemented with questions on demographic and lifestyle characteristics. The questionnaire was self-completed by the older children (as per the ISAAC protocol) and by the parents of children in the case of the younger age-group. The study was approved by the Cyprus Bioethics Committee (EEBK/EP/2006/28). Informed written parental consent was obtained in all cases.

\section{Definition of outcome variables}

Based on answers given to questions of the ISAAC questionnaire, we studied the following outcomes as defined previously [1,2]: Current wheeze, Severity of asthma, Current eczema, and Current allergic rhinoconjuctivitis. We have also explored potential differences in diagnosis of asthma, hay fever and eczema as well as report of ever wheeze between children from the two communities, but we chose to focus the analysis to reported symptoms rather than diagnostic labels (i.e. report of diagnosis of asthma, hay fever or eczema) in order to avoid confounding effects relating to possible differential use and/or understanding of diagnostic terms between the two communities.

While the Greek version of the ISAAC questionnaire has not been officially validated, the translation used in this study is the only available Greek version of the ISAAC core questionnaire, which was adopted by the ISAAC study and has been used by the two ISAAC centers in Greece (Athens, Thessaloniki). Furthermore, it has been used ever since as a standard tool in several studies in Greece, including the PANACEA epidemiological study [14], and it has been recently shown that reported symptoms correlate well with objective measures of allergy (skin prick testing) [15]. The Turkish version of the ISAAC questionnaire was tested in a pilot study conducted three months before the ISAAC study. The parental self-administered questionnaire and the faceto-face interview with the parents were found to be concordant [16].

\section{Definition of predictor variables}

In order to describe the socio-demographic characteristics and the prevalence of risk factors of the sample participants from the two communities, the following variables were selected a priori: gender, nationality (defined as: "Both parents are Cypriots (either G/C or $\mathrm{T} / \mathrm{C})$ " vs "At least one parent is not Cypriot"), family 
history of allergies (i.e. positive report of asthma, eczema or hay fever in any sibling and/or parent), passive smoking (categorized as: none, up to 20, and more than 20 cigarettes smoked daily in the house), parental level of education (categorized in terms of the highest level of education attained by at least one of the parents), ownership of pets or other animals kept in the household or yard of the house, exposure to any farm animal (i.e. sheep and/or cow) at the house environment, number of older siblings and area of residence. Area of residence was characterized as urban if the family address was located within the boundaries or in the wider metropolitan areas in geographic continuity with one of the main cities on the island. If the family address was in a settlement not in geographic continuity with any of the cities, it was classified as semi-rural or rural depending on whether the population exceeded or not 1500 residents respectively. Parents of the 7-8 year-old participants also provided information on maternal smoking habits during pregnancy of the participating child, mode of delivery, birth weight, duration of exclusive breastfeeding, nursery attendance in first year of life, bedroom sharing up to age of 5 years while children in the older age group were only asked about their own smoking habits.

\section{Statistical analyses}

For each community and age-group, prevalence estimates and $95 \%$ confidence intervals (CI) of asthma and allergic symptoms were estimated, as per ISAAC protocol $[1,2]$. In order to investigate differences between the two communities, the relative differences in the prevalence outcomes were expressed as odds ratios (OR) with their corresponding 95\% CI, as estimated in logistic regression models. Multivariable models were used to investigate the extent to which differences in socio-demographic and other risk factors between the participating children from the two communities account for any observed differences in the study outcomes. A hierarchical approach was used whereby the crude estimates (model 1) were adjusted for sociodemographic characteristics and a priori selected main risk factors for asthma/allergy, excluding (model 2) and including (model 3) family history of allergy. Post-hoc, this proved particularly important due to the striking difference observed in self-reported family history between the two communities. In order to explore whether the strength of the association between any of the investigated factors (including family history of allergy) and study outcomes was differential in the two communities, models include an interaction term between community and each factor in turn. Statistical significance of the interaction terms was assessed in Likelihood Ratio Tests (LRT) for effect modification comparing models with and without the interaction terms. All analyses were performed using the statistical software $\mathrm{R}$ (version 2.12.1).

\section{Results}

\section{Population characteristics}

In total, 4569 children aged $7-8$ years $(2216 \mathrm{G} / \mathrm{C}$ and $2353 \mathrm{~T} / \mathrm{C}, 48 \%$ and $65 \%$ response rate respectively) and 5587 children aged 13-14 years (2452 G/C and $3135 \mathrm{~T} / \mathrm{C}, 44 \%$ and $87 \%$ response rate respectively) participated in the study. Table 1 presents the sociodemographic and other risk characteristics of the $\mathrm{G} / \mathrm{C}$ and $\mathrm{T} / \mathrm{C}$ children, revealing a different profile in terms of almost all the parameters examined.

As many as $59.1 \%$ of $7-8$ year old $\mathrm{T} / \mathrm{C}$ resided in less urbanized environments, $52.3 \%$ reported bedroom sharing in first 5 years of life and $4.7 \%$ reported keeping a farm animal in the home environment, as opposed to $33.5 \%, 37.4 \%$ and $0.6 \%$ respectively amongst $\mathrm{G} / \mathrm{C}$ children (all $\mathrm{p}<0.01$ ). While many presumably protective factors as per the hygiene hypothesis were more prevalent in the $\mathrm{T} / \mathrm{C}$ community, nursery attendance in first year of life $(9.3 \%$ vs $4.7 \%, \mathrm{p}<0.01)$ and presence of older siblings $(62.3 \%$ vs $49.2 \%, \mathrm{p}<0.01)$ were higher among $7-8$ yearold $\mathrm{G} / \mathrm{C}$ children. Furthermore, more $\mathrm{T} / \mathrm{C}$ children were exclusively breastfed $(78.2 \%$ vs $53.7 \%, \mathrm{p}<0.01)$ while rates of caesarian delivery were similarly high in both communities (39\% vs $31.7 \%, \mathrm{p}<0.01$ ), even though the difference was statistically significant due to the large size of the survey.

In contrast, exposure to tobacco smoke was higher in the $\mathrm{T} / \mathrm{C}$ community, both as passive smoking at the time of survey $(53.3 \%$ vs $39.9 \%, \mathrm{p}<0.01)$ as well as during pregnancy $(10.8 \%$ vs $2.9 \%, \mathrm{p}<0.01)$. A similar picture emerged in the 13-14 year old group. Finally, as expected, a higher level of educational attainment was recorded amongst parents in the $\mathrm{G} / \mathrm{C}$ community. In contrast, the proportion reporting family history of allergies was strikingly higher in the G/C community with $37 \%$ vs $19.5 \%,(p<0.01)$ in the younger and $16.5 \%$ vs $10.9 \%$ $(\mathrm{p}<0.01)$ in the older age-group.

\section{Prevalence of asthma and allergic symptoms in the $\mathrm{G} / \mathrm{C}$ and $\mathrm{T} / \mathrm{C}$ communities}

Table 2 presents age- and community-specific prevalence estimates of asthma and allergy symptoms. To better visualize the prevalence estimates in the two communities for individual study outcomes, as well as their interrelationships, proportional Venn diagrams are presented in Figure 1. Current eczema was far more prevalent among young $\mathrm{G} / \mathrm{C}$ children compared to $\mathrm{T} / \mathrm{C}$ children, while the reverse is true for rhinoconjuctivitis. In the older age-group, while the prevalence of eczema appears similar in the two communities, the prevalence 
Table 1 Socio-demographic and other risk characteristics of the participating children aged 7-8 and 13-14 from the Greek-Cypriot and Turkish-Cypriot communities

\begin{tabular}{|c|c|c|c|c|c|c|}
\hline \multirow[b]{2}{*}{$\begin{array}{l}\text { Participant characteristics } \\
\text { (expressed as percentages) }\end{array}$} & \multicolumn{3}{|c|}{ Children aged 7-8 } & \multicolumn{3}{|c|}{ Children aged 13-14 } \\
\hline & $\begin{array}{c}\mathrm{G} / \mathrm{C} \\
(\mathrm{n}=2216)\end{array}$ & $\begin{array}{c}T / C \\
(n=2353)\end{array}$ & $\mathbf{p}^{\dagger}$ & $\begin{array}{c}G / C \\
(n=2452)\end{array}$ & $\begin{array}{c}\mathrm{T} / \mathrm{C} \\
(\mathrm{n}=3135)\end{array}$ & $p^{+}$ \\
\hline Female gender (\%) & 49.5 & 50.6 & & 48.2 & 51.7 & \\
\hline \multicolumn{7}{|l|}{ Parental education (\%) } \\
\hline Only one secondary education & 5.3 & 49.9 & & 13.0 & 43.0 & \\
\hline Both secondary education & 40.9 & 30.3 & & 46.7 & 36.8 & \\
\hline Only one tertiary education & 24.1 & 12.8 & & 21.2 & 11.6 & \\
\hline Both tertiary education & 29.8 & 7.1 & * & 19.0 & 8.6 & $*$ \\
\hline \multicolumn{7}{|l|}{ Area of residence (\%) } \\
\hline Urban & 66.5 & 40.9 & & 65.9 & 46.5 & \\
\hline Sub-rural & 21.0 & 24.3 & & 18.2 & 22.1 & \\
\hline Rural & 12.5 & 34.8 & * & 15.9 & 31.4 & $*$ \\
\hline Family history of allergies (\%) & 37.0 & 19.5 & * & 16.5 & 10.9 & $*$ \\
\hline \multicolumn{7}{|l|}{ Older siblings (\%) } \\
\hline None & 38.7 & 50.8 & & 26.3 & 44.4 & \\
\hline 1 & 34.3 & 34.3 & & 37.8 & 34.4 & \\
\hline$\geq 2$ & 27.0 & 14.9 & * & 35.9 & 21.2 & * \\
\hline \multicolumn{7}{|l|}{ Passive smoking (\%) } \\
\hline Not at all & 60.1 & 46.7 & & 49.7 & 43.1 & \\
\hline Up to 20 cigarettes/day & 25.3 & 40.3 & & 35.5 & 48.3 & \\
\hline More than 20 cigarettes/day & 14.7 & 13.0 & * & 14.8 & 8.6 & \\
\hline Animals at home/yard (\%) & 42.6 & 32.4 & * & 56.2 & 48.0 & * \\
\hline Farm animal at home/yard (\%) & 0.6 & 4.7 & * & 0.5 & 4.2 & $*$ \\
\hline Caesarian delivery $(\%)^{\ddagger}$ & 31.7 & 39.0 & * & $-\cdots$ & $-\cdots$ & \\
\hline Birth weight $<2500 \mathrm{gr}(\%)^{\ddagger}$ & 13.9 & 18.0 & * & -- & $-\cdots$ & \\
\hline \multicolumn{7}{|l|}{ Duration of breastfeeding $(\%)^{\ddagger}$} \\
\hline Not at all & 46.8 & 21.8 & & $\cdots$ & $-\cdots$ & \\
\hline$<4$ months & 32.5 & 24.2 & & $-\cdots$ & --- & \\
\hline$\geq 4$ months & 20.6 & 54.0 & * & $-\cdots$ & $-\cdots$ & \\
\hline Bedroom sharing $(\%)^{\ddagger}$ & 37.4 & 52.3 & * & $-\cdots$ & $-\cdots$ & \\
\hline Nursery in first year of life $(\%)^{\ddagger}$ & 9.3 & 4.7 & * & $-\cdots$ & $-\cdots$ & \\
\hline Maternal smoking during pregnancy $(\%)^{\ddagger}$ & 2.9 & 10.8 & * & $-\cdots$ & $-\cdots$ & \\
\hline Active smoking $(\%)^{\ddagger}$ & $-\cdots$ & -- & & 1.7 & 1.3 & \\
\hline
\end{tabular}

* P-value of $\mathrm{X}^{2}$ test comparing the $\mathrm{G} / \mathrm{C}$ and $\mathrm{T} / \mathrm{C}$ communities $<0.01$.

₹ Information on these variables was not obtained from the 13-14 year-old group, while active smoking was not included in the 7-8 year-old questionnaires.

of rhinoconjuctivitis remains more prevalent among $\mathrm{T} / \mathrm{C}$ children.

With the exception of eczema, consistently lower prevalence for all respiratory outcomes was observed among children in the G/C community in both age-groups. The prevalence of current wheeze among 7-8 year-olds was $8.7 \%$ in $\mathrm{G} / \mathrm{C}$ vs $11.4 \%$ in T/C (OR: $0.74,95 \% \mathrm{CI}$ : 0.61-0.90) whereas the equivalent figures among 1314 year-olds were $4.1 \%$ vs $5.6 \%$ (OR 0.73 , CI: $0.56-0.95$ ). Similarly, the prevalence of severe asthma among younger children was $2.6 \%$ vs $4.9 \%$ (OR 0.52 , CI: $0.37-0.71$ ) and $1.8 \%$ vs $3.0 \%$ (OR $0.61, \mathrm{CI}: 0.42-0.87$ ) in the older children. After controlling for participants' characteristics in multivariable models, there was only slight attenuation in the estimates. However, while adjusted Odds Ratios (aORs) were lower than 1 for all outcomes, only current wheeze in the younger age-group (aOR 0.73, CI: 0.54-0.98) and severe asthma in the older age-group (aOR 0.52, CI: 0.34-0.85) remained statistically significant. Adjusted ORs for severe asthma in the younger age-group and 
Table 2 The prevalence of asthma and allergic symptoms among children aged 7-8 and 13-14 from the Greek-Cypriot and Turkish-Cypriot communities along with unadjusted and adjusted odds ratios comparing the two communities

\begin{tabular}{|c|c|c|c|c|c|}
\hline \multirow[t]{3}{*}{ Outcome } & \multirow{3}{*}{$\begin{array}{c}\mathrm{G} / \mathrm{C} \\
\text { Prevalence } \\
(95 \% \mathrm{Cl})\end{array}$} & \multirow{3}{*}{$\begin{array}{c}\mathrm{T} / \mathrm{C} \\
\text { Prevalence } \\
(95 \% \mathrm{Cl})\end{array}$} & \multicolumn{3}{|c|}{$G / C$ Vs $T / C$} \\
\hline & & & Unadjusted & Adjusted OR† & Adjusted OR \\
\hline & & & OR $(95 \% \mathrm{Cl})$ & $(95 \% \mathrm{Cl})$ & $(95 \% C l)$ \\
\hline \multicolumn{6}{|c|}{ Children 7-8 years of age } \\
\hline \multirow[t]{2}{*}{ Current Wheeze } & 8.71 & 11.43 & 0.74 & 0.73 & 0.84 \\
\hline & $(7.60,9.96)$ & $(10.21,12.78)$ & $(0.61,0.90)$ & $(0.54,0.98)$ & $(0.63,1.12)$ \\
\hline \multirow[t]{2}{*}{ Severe Asthma } & 2.61 & 4.93 & 0.52 & 0.67 & 0.78 \\
\hline & $(2.02,3.37)$ & $(4.13,5.88)$ & $(0.37,0.71)$ & $(0.41,1.07)$ & $(0.49,1.24)$ \\
\hline \multirow[t]{2}{*}{ Current Rhinoconjuctivitis } & 2.60 & 4.90 & 0.52 & 0.61 & 0.70 \\
\hline & $(2.00,3.36)$ & $(4.09,5.84)$ & $(0.37,0.71)$ & $(0.38,0.99)$ & $(0.43,1.12)$ \\
\hline \multirow[t]{2}{*}{ Current Eczema } & 4.72 & 3.53 & 1.36 & 1.22 & 1.38 \\
\hline & $(3.91,5.69)$ & $(2.85,4.35)$ & $(1.01,1.83)$ & $(0.79,1.91)$ & $(0.90,2.13)$ \\
\hline \multicolumn{6}{|c|}{ Children $13-14$ years of age } \\
\hline \multirow[t]{2}{*}{ Current Wheeze } & 4.12 & 5.59 & 0.73 & 0.76 & 0.83 \\
\hline & $(3.40,4.99)$ & $(4.84,6.46)$ & $(0.56,0.93)$ & $(0.54,1.05)$ & $(0.60,1.14)$ \\
\hline \multirow[t]{2}{*}{ Severe Asthma } & 1.82 & 2.97 & 0.61 & 0.52 & 0.62 \\
\hline & $(1.36,2.43)$ & $(2.43,3.62)$ & $(0.42,0.87)$ & $(0.34,0.85)$ & $(0.38,0.99)$ \\
\hline \multirow[t]{2}{*}{ Current Rhinoconjuctivitis } & 4.33 & 6.64 & 0.64 & 0.72 & 0.76 \\
\hline & $(3.59,5.22)$ & $(5.81,7.58)$ & $(0.50,0.81)$ & $(0.52,1.00)$ & $(0.55,1.06)$ \\
\hline \multirow[t]{2}{*}{ Current Eczema } & 2.22 & 2.05 & 1.09 & 1.21 & 1.29 \\
\hline & $(1.71,2.89)$ & $(1.61,2.61)$ & $(0.75,1.56)$ & $(0.73,2.00)$ & $(0.78,2.14)$ \\
\hline
\end{tabular}

† For 7-8 years old: Adjusted for sex, parent's level of education, area of residence, family history of allergy, number of siblings, passive smoking, animals at home, maternal smoking during pregnancy, mode of delivery, birth weight, exclusive breastfeeding duration and bedroom sharing. For 13-14 years old: Adjusted for sex, parent's level of education, area of residence, family history of allergy, number of siblings, passive and active smoking and animals at home.

¥ Adjusted for all the above participant characteristics except family history of allergy.

current wheeze in the older age-group were no longer statistically significant at the $5 \%$ level.

Similarly, a lower prevalence of current rhinoconjuctivitis was also observed in G/C community, $2.6 \%$ vs $4.9 \%$ among the $7-8$ year olds and $4.3 \%$ vs $6.6 \%$ among 13-14 year olds, while in this case the community effect remained significant even after controlling for the different risk characteristics of the samples (aOR 0.61, CI: 0.38-0.99 and aOR 0.72, CI: 0.52-1.00 respectively).

In contrast, a slightly higher prevalence of current eczema symptoms was found among the 7-8 year-olds in G/C community, $4.7 \%$ vs $3.5 \%$ (OR 1.36 , CI: $1.01-1.83$ ), while no difference was observed in the older agegroup. Nevertheless, the aOR for current eczema were not statistically significant in either group suggesting no independent community effect on the prevalence of eczema after controlling for risk factors.

In a subgroup analysis of children whose parents are both of Cypriot origin (i.e. either both G/C or both $\mathrm{T} /$ $\mathrm{C}$ in each community respectively) the results remained largely unchanged (see Table 3). The prevalence estimates in the $\mathrm{T} / \mathrm{C}$ community decreased for all study outcomes, and as a result the gap between the two communities appeared smaller (or bigger in the case of eczema). While this is suggestive of higher prevalence among the children in the T/C community whose parents are not both of $\mathrm{T} / \mathrm{C}$ origin (e.g. immigrant groups), the prevalence estimates in the $\mathrm{T} / \mathrm{C}$ are still higher for all study outcomes (other than eczema) whereas confidence intervals become wider as a result of the reduced sample size.

The prevalence estimates, as well as the effect of adjusting for differences in the socio-demographic and other risk characteristics of the participants are also presented graphically in Figure 2. It is apparent that the $\mathrm{G} / \mathrm{C}$ vs $\mathrm{T} / \mathrm{C}$ odds ratios appear slightly stronger in the case of eczema and attenuate in the case of all other outcomes after removing family history of allergies from the multivariable models. The only exception was the case of severe asthma in the older age-group which still remains significantly less prevalent in the G/C community (aOR 0.62, CI: 0.38-0.99). This suggests that the community effect in $\mathrm{G} / \mathrm{C}$ appears particularly favorable compared to the $\mathrm{T} / \mathrm{C}$ for wheeze and rhinoconjuctivitis given the much higher prevalence of reported family predisposition amongst G/C children.

Despite the much lower reported prevalence of family history of allergy among parents of $\mathrm{T} / \mathrm{C}$ children, a consistently higher prevalence of diagnosis of asthma 

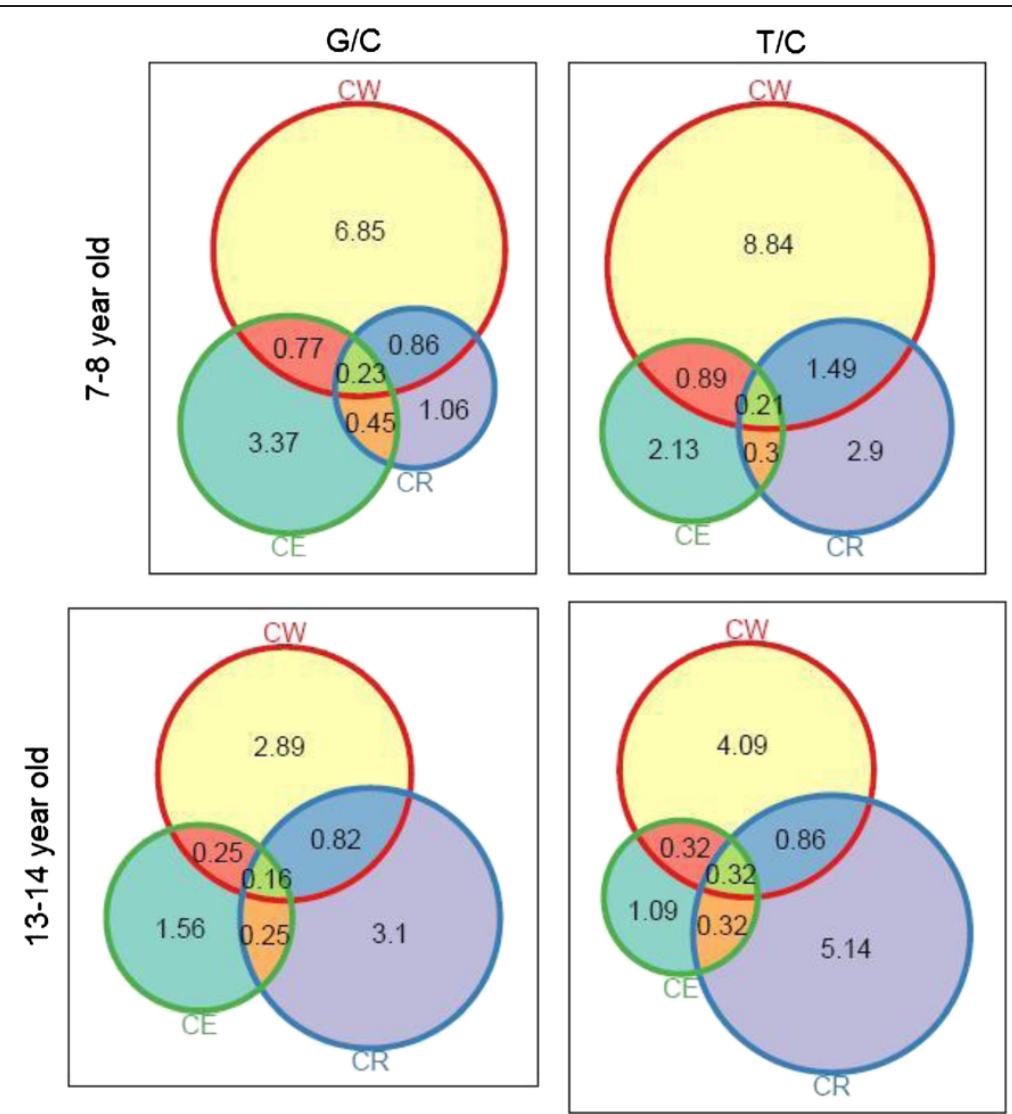

Figure 1 Proportional Venn diagrams of the prevalence of asthma and allergic symptoms in children of the $\mathrm{G} / \mathrm{C}$ and $\mathrm{T} / \mathrm{C}$ communities. Proportional Venn diagrams presenting the prevalence of current wheeze (CW), current allergic rhinoconjuctivitis (CR) and current eczema (CE) in 7-8 and 13-14 year-old children from the Greek-Cypriot and Turkish-Cypriot communities.

(19.3\% vs $17.8 \%$ in children aged $7-8$ and $15.4 \%$ vs $11.3 \%$ in children aged $13-14)$ and hay-fever (11.6\% vs $5.4 \%$ in children aged $7-8$ and $10.2 \%$ vs $2.9 \%$ in children aged 13-14) was observed in the $\mathrm{T} / \mathrm{C}$ community. The only exception was the diagnosis of eczema which was also the only symptom which exhibited higher prevalence in the $\mathrm{G} / \mathrm{C}$ community.

\section{Association of asthma and allergic symptoms with predictors involved in the hygiene hypothesis}

We observed associations between several factors projected in the hygiene hypothesis with asthma and allergic symptoms but these were not consistent across all study outcomes or both age-groups (see Table 4). For instance, adjusted ORs for current wheeze (aOR: 0.72, 95\% CI: 0.53, 0.98), severe asthma (aOR: 0.56, 95\% CI: 0.56, 0.91) and current eczema (aOR:0.36, 95\% CI: 0.20, 0.61) among children aged 7-8 years with two or more older siblings suggested a protective effect. Nevertheless, this was not generally the case with the older age-group. While no overall effect was observed in this age-group, there was some evidence to suggest that the protective effect of sibling order, at least for wheezing, may be restricted to G/C children (LRT p-value for effect modification with community<0.05). In contrast, nursery attendance in first year of life was not associated with any of the study outcomes while bedroom sharing was associated with an elevated risk for severe asthma among the younger age-group (aOR 1.69, 95\% CI: 1.17, 2.43). Furthermore, exposure to farm animals was not associated with any of the study outcomes in any agegroup while rural environment appeared protective for wheezing, but not eczema and rhinoconjuctivitis, only in the older age group. In the case of rhinoconjuctivitis, there was some evidence that a rural environment may be protective amongst older $\mathrm{G} / \mathrm{C}$ children but, if anything, the opposite was true in the case of $\mathrm{T} / \mathrm{C}$ children. Other than the few exceptions mentioned here, there was generally no statistical evidence that the strength of association between any of these risk factors and study outcomes differed by community.

\section{Association of asthma and allergic symptoms with other risk characteristics}

Table 5 presents the unadjusted and adjusted ORs of asthma and allergic symptoms with other potential risk 
Table 3 The prevalence of asthma and allergic symptoms among children aged 7-8 and 13-14 from the Greek-Cypriot and Turkish-Cypriot communities, restricting the analysis to those children whose parents are both of Cypriot origin, along with unadjusted and adjusted odds ratios comparing the two communities

\begin{tabular}{|c|c|c|c|c|c|}
\hline \multirow[t]{3}{*}{ Outcome } & \multirow{3}{*}{$\begin{array}{c}\mathrm{G} / \mathrm{C} \\
\text { Prevalence } \\
(95 \% \mathrm{Cl})\end{array}$} & \multirow{3}{*}{$\begin{array}{c}\mathrm{T} / \mathrm{C} \\
\text { Prevalence } \\
(95 \% \mathrm{Cl})\end{array}$} & \multicolumn{3}{|c|}{$G / C$ Vs $T / C$} \\
\hline & & & Unadjusted & Adjusted OR† & Adjusted OR \\
\hline & & & OR $(95 \% \mathrm{Cl})$ & $(95 \% \mathrm{Cl})$ & $(95 \%$ Cl) \\
\hline \multicolumn{6}{|c|}{ Children 7-8 years of age } \\
\hline \multirow[t]{2}{*}{ Current Wheeze } & 8.94 & 10.91 & 0.80 & 0.78 & 0.93 \\
\hline & $(7.70,10.36)$ & $(8.95,13.23)$ & $(0.61,1.06)$ & $(0.54,1.14)$ & $(0.65,1.33)$ \\
\hline \multirow[t]{2}{*}{ Severe Wheeze } & 2.56 & 3.55 & 0.71 & 0.82 & 0.96 \\
\hline & $(1.92,3.41)$ & $(2.49,5.06)$ & $(0.45,1.16)$ & $(0.44,1.55)$ & $(0.53,1.79)$ \\
\hline \multirow[t]{2}{*}{ Current Rhinoconjuctivitis } & 2.60 & 3.20 & 0.81 & 0.88 & 1.01 \\
\hline & $(1.95,3.46)$ & $(2.19,4.64)$ & $(0.50,1.33)$ & $(0.46,1.71)$ & $(0.53,1.93)$ \\
\hline \multirow[t]{2}{*}{ Current Eczema } & 5.00 & 3.31 & 1.54 & 1.41 & 1.60 \\
\hline & $(4.08,6.12)$ & $(2.28,4.77)$ & $(1.00,2.43)$ & $(0.81,2.53)$ & $(0.93,2.84)$ \\
\hline \multicolumn{6}{|c|}{ Children 13-14 years of age } \\
\hline \multirow[t]{2}{*}{ Current Wheeze } & 3.99 & 4.85 & 0.82 & 0.97 & 1.02 \\
\hline & $(3.23,4.91)$ & $(3.80,6.17)$ & $(0.58,1.14)$ & $(0.65,1.44)$ & $(0.69,1.51)$ \\
\hline \multirow[t]{2}{*}{ Severe Wheeze } & 1.85 & 2.43 & 0.76 & 0.76 & 0.84 \\
\hline & $(1.36,2.53)$ & $(1.72,3.43)$ & $(0.47,1.23)$ & $(0.42,1.38)$ & $(0.47,1.49)$ \\
\hline \multirow[t]{2}{*}{ Current Rhinoconjuctivitis } & 4.40 & 3.90 & 1.14 & 1.07 & 1.08 \\
\hline & $(3.60,5.37)$ & $(2.96,5.11)$ & $(0.80,1.63)$ & $(0.71,1.64)$ & $(0.71,1.64)$ \\
\hline \multirow[t]{2}{*}{ Current Eczema } & 2.17 & 1.00 & 2.18 & 1.79 & 1.86 \\
\hline & $(1.63,2.89)$ & $(0.59,1.72)$ & $(1.21,4.22)$ & $(0.91,3.70)$ & $(0.96,3.83)$ \\
\hline
\end{tabular}

+ For 7-8 years old: Adjusted for sex, parent's level of education, area of residence, family history of allergy, number of siblings, passive smoking, animals at home, maternal smoking during pregnancy, mode of delivery, birth weight, exclusive breastfeeding duration and bedroom sharing. For 13-14 years old: Adjusted for sex, parent's level of education, area of residence, family history of allergy, number of siblings, passive and active smoking and animals at home.

\# Adjusted for all the above participant characteristics except family history of allergy.

factors. As expected, allergic background was generally the strongest and most consistent predictor of reported symptoms, with aORs of a magnitude of 2 to 5 across all outcomes in both age-groups. In the older age-group, active smoking was also a strong predictor with aORs of 4.49 (95\% CI: 2.17, 8.64) for current wheeze, 6.03 (95\% CI: $2.46,13.17)$ for severe asthma and 2.60 (95\% CI: $1.15,5.27)$ for current rhinoconjuctivitis. Having animal (s) at home was a significant risk factor for current eczema (aOR: 2.35, 95\% CI: 1.54, 3.65) and current rhinoconjuctivitis (aOR:1.40, 95\% CI:1.08, 1.82) only in the older children. Similarly, exposure to passive smoking in the household also carried a more pronounced effect in the older age-group, with significant associations with current wheeze (aOR:1.57, 95\% CI: 1.04, 2.32), current eczema (aOR: 1.81, 95\% CI: 1.02, 3.13) and current rhinoconjuctivitis (aOR: $2.73,95 \%$ CI: 1.91, 3.89) in those exposed to 20 or more cigarettes' smoke daily. Some statistical evidence of effect modification by community was observed for exposure to tobacco smoke in the younger age-group, where association with wheeze was only observed amongst $\mathrm{T} / \mathrm{C}$ (aOR: $1.56,95 \% \mathrm{CI}$ : 1.19, 2.05) but not G/C children (aOR: 0.86, 95\% CI:
$0.59,1.22)$. Exposure to maternal smoking during pregnancy was also found to be associated with current wheeze (aOR: 1.55, 95\% CI: 1.08, 2.17) and current eczema (aOR: 1.84, 95\% CI: 1.04, 3.11) in the younger children. In the case of eczema, the association with maternal smoking during pregnancy is restricted to $\mathrm{T} / \mathrm{C}$ children (aOR: 2.44, 95\% CI: 1.31, 4.35) since a similar effect was not observed among G/C children (aOR: 0.31, 95\% CI: 0.02, 1.57). Finally, the level of parental education did not appear to be associated with any of the study outcomes among the older children, whereas in the younger children associations were sporadic and no suggestive of a clear pattern. Other than the few exceptions mentioned here, there was generally no statistical evidence that different factors were important in the two communities or that the strength of association between any of these risk factors and the study outcomes differed by community.

\section{Association of family history of allergy with asthma and} allergic symptoms

The markedly lower frequency of family history reported in the $\mathrm{T} / \mathrm{C}$ community is perhaps suggestive that there 
7-8
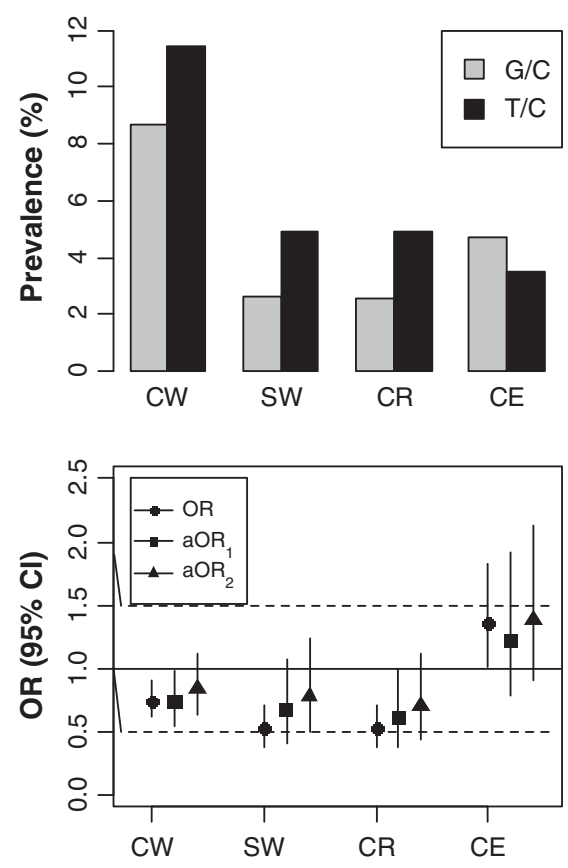

13-14
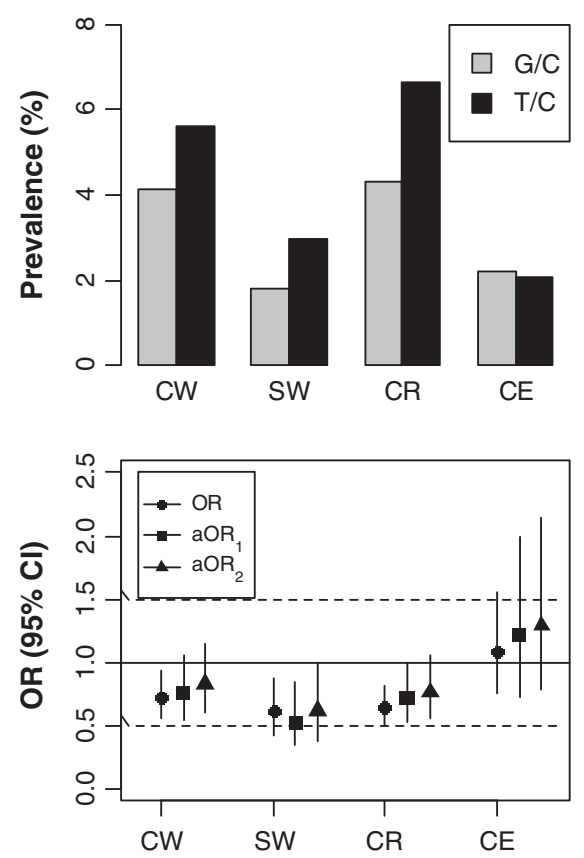

Figure 2 Prevalence and adjusted odds ratios of asthma and allergic symptoms in children of the G/C and T/C communities. Prevalence and odds ratios of asthma and allergic symptoms in 7-8 and 13-14 year old children from the Greek-Cypriot as compared to the Turkish-Cypriot community before and after adjusting for potential risk factors (including and excluding family history of allergies).

might have been underestimation, and thus misclassification in the case of $\mathrm{T} / \mathrm{C}$, in which case we would expect that the strength of association between the study outcomes and family history would be weaker in T/C. At least in the younger age-group, adjusted associations of all outcomes with family history of allergies were consistently stronger among the G/C community. Nevertheless, we found no statistical evidence of effect modification by community on the association of family history of allergy with asthma and allergic symptoms (Table 6).

\section{Discussion}

This is the first study to present estimates of the prevalence of allergic disorders in the two communities of Cyprus that have been living apart on either side of the division line on the island for nearly 40 years. In the G/C community, prevalence of current wheeze in 78 year-old children assessed with the use of ISAAC questionnaire was $8.7 \%$ in 2008 , demonstrating a rising trend from the previous recorded estimate of $6.9 \%$ in $2000-01$ [12]. In the $\mathrm{T} / \mathrm{C}$ community, there is currently no evidence regarding the temporal prevalence trends of allergic conditions in childhood. The literature is restricted to a single study, performed in 1999, when prevalence of current wheeze among children aged 6-14 years was estimated at 4.8\% [13]. Although the ISAAC protocol was also employed in this study, no direct comparisons can be made with our findings due to the different age spectrum of the study populations.

The main strength of our report is the use of the same standardized protocol to study concurrently childhood allergies in large population samples from two communities that live apart on a small divided island. However, due to the cross-sectional nature of the study and absence of objective markers of atopy no causative inferences can be made between the identified risk factors and study outcomes. The response rate among the $\mathrm{G} / \mathrm{C}$ community was lower than the one in the $\mathrm{T} / \mathrm{C}$ community, possibly as a result of the steady rise in the number of surveys performed in G/C schools in the last decade. Nevertheless, we do not think that this has compromised the representativeness of the G/C sample since the socio-demographic characteristics of the participants compare very favorably with the profile recorded in other epidemiological studies performed at a similar time in this population with much higher response rates; details of this, and other sensitivity analyses performed to assess the possible magnitude of selection bias in the G/C sample were published in a previous report [12]. Even though the socio-demographic composition of the G/C sample supports its representativeness, we cannot entirely rule out that the findings are not affected by the lower 
Table 4 Unadjusted and adjusted odds ratios of asthma and allergic symptoms in children aged 7-8 and 13-14 from the Greek-Cypriot and Turkish-Cypriot communities in relation to risk factors projected in the hygiene hypothesis

\begin{tabular}{|c|c|c|c|c|c|c|c|c|}
\hline & \multicolumn{8}{|c|}{ Children 7-8 years of age } \\
\hline & \multicolumn{2}{|c|}{ Current wheeze } & \multicolumn{2}{|c|}{ Severe asthma } & \multicolumn{2}{|c|}{ Current eczema } & \multicolumn{2}{|c|}{ Current Rhinoconjuctivitis } \\
\hline & $\begin{array}{c}\text { Unadjusted OR } \\
(95 \% \mathrm{Cl})\end{array}$ & $\begin{array}{l}\text { Adjusted ORt } \\
(95 \% \mathrm{Cl})\end{array}$ & $\begin{array}{l}\text { Unadjusted OR } \\
(95 \% \mathrm{Cl})\end{array}$ & $\begin{array}{l}\text { Adjusted ORt } \\
(95 \% \mathrm{Cl})\end{array}$ & $\begin{array}{c}\text { Unadjusted OR } \\
(95 \% \mathrm{Cl})\end{array}$ & $\begin{array}{c}\text { Adjusted ORt } \\
(95 \% \mathrm{Cl})\end{array}$ & $\begin{array}{c}\text { Unadjusted OR } \\
(95 \% \mathrm{Cl})\end{array}$ & $\begin{array}{c}\text { Adjusted ORt } \\
(95 \% \mathrm{Cl})\end{array}$ \\
\hline \multicolumn{9}{|l|}{ Older sibling } \\
\hline 1 (Vs None) & $0.86(0.69,1.07)$ & $0.76(0.59,0.97)$ & $1.08(0.77,1.51)$ & $0.80(0.55,1.16)$ & $0.87(0.63,1.20)$ & $0.70(0.48,1.00)$ & $0.87(0.61 .1 .23)$ & $0.76(0.51,1.11)$ \\
\hline$\geq 2$ (Vs None) & $0.83(0.63,1.08)$ & $0.72(0.53,0.98)$ & $0.82(0.52,1.27)$ & $0.56(0.33,0.91)$ & $0.48(0.29,0.75)$ & $0.36(0.20,0.61)$ & $0.97(0.63,1.46)$ & $0.77(0.47,1.22)$ \\
\hline $\begin{array}{l}\text { Farm animal at } \\
\text { home }\end{array}$ & $1.11(0.62,1.87)$ & $0.99(0.54,1.72)$ & $1.13(0.46,2.36)$ & $0.97(0.38,2.10)$ & $1.26(0.48,2.74)$ & $1.33(0.49,3.04)$ & $1.26(0.52,2.62)$ & $1.02(0.40,2.21)$ \\
\hline \multicolumn{9}{|l|}{ Area of residence } \\
\hline $\begin{array}{l}\text { Sub-rural (Vs } \\
\text { Rural) }\end{array}$ & $1.04(0.79,1.37)$ & $1.09(0.82,1.45)$ & $1.40(0.92,2.13)$ & $1.49(0.96,2.31)$ & $1.01(0.64,1.61)$ & $1.12(0.69,1.80)$ & $1.03(0.67,1.57)$ & $1.08(0.70,1.68)$ \\
\hline Urban (Vs Rural) & $0.87(0.69,1.12)$ & $0.87(0.67,1.13)$ & $1.04(0.70,1.54)$ & $1.02(0.67,1.56)$ & $1.20(0.82,1.79)$ & $1.20(0.79,1.85)$ & $0.89(0.61,1.30)$ & $0.83(0.56,1.26)$ \\
\hline Bedroom sharing & $1.09(0.90,1.33)$ & $1.20(0.95,1.52)$ & $1.61(1.18,2.20)$ & $1.69(1.17,2.43)$ & $1.00(0.75,1.36)$ & $1.29(0.90,1.86)$ & $1.16(0.85,1.58)$ & $1.17(0.82,1.69)$ \\
\hline \multirow{4}{*}{$\begin{array}{l}\text { Nursery } \\
\text { attendance }\end{array}$} & $1.25(0.84,1.96)$ & $1.28(0.85,2.03)$ & $0.81(0.47,1.53)$ & $0.85(0.49,1.62)$ & $0.88(0.53,1.58)$ & $0.84(0.49,1.52)$ & $0.97(0.55,1.92)$ & $1.05(0.58,2.10)$ \\
\hline & \multicolumn{8}{|c|}{ Children $13-14$ years of age } \\
\hline & \multicolumn{2}{|c|}{ Current wheeze } & \multicolumn{2}{|c|}{ Severe asthma } & \multicolumn{2}{|c|}{ Current eczema } & \multicolumn{2}{|c|}{ Current Rhinoconjuctivitis } \\
\hline & $\begin{array}{l}\text { Unadjusted OR } \\
(95 \% \mathrm{Cl})\end{array}$ & $\begin{array}{c}\text { Adjusted OR } \neq \\
(95 \% \mathrm{Cl})\end{array}$ & $\begin{array}{c}\text { Unadjusted OR } \\
(95 \% \mathrm{Cl})\end{array}$ & $\begin{array}{c}\text { Adjusted OR } \neq \\
(95 \% \mathrm{Cl})\end{array}$ & $\begin{array}{c}\text { Unadjusted OR } \\
(95 \% \mathrm{CI})\end{array}$ & $\begin{array}{c}\text { Adjusted OR } \neq \\
(95 \% \mathrm{Cl})\end{array}$ & $\begin{array}{l}\text { Unadjusted OR } \\
(95 \% \mathrm{Cl})\end{array}$ & $\begin{array}{c}\text { Adjusted OR } \neq \\
(95 \% \mathrm{CI})\end{array}$ \\
\hline \multicolumn{9}{|l|}{ Older sibling } \\
\hline 1 (Vs None) & $0.87(0.65,1.16)$ & $0.87(0.64,1.19)$ & $1.00(0.67,1.48)$ & $1.03(0.66,1.58)$ & $0.86(0.54,1.37)$ & $0.84(0.50,1.39)$ & $1.33(1.00 .1 .77)$ & $1.29(0.95,1.76)$ \\
\hline$\geq 2$ (Vs None) & $0.82(0.59,1.13)$ & $0.90(0.64,1.26)$ & $0.86(0.53,1.35)$ & $0.95(0.57,1.55)$ & $1.43(0.92,2.24)$ & $1.40(0.86,2.27)$ & $1.59(1.17,2.15)$ & $1.41(1.02,1.96)$ \\
\hline $\begin{array}{l}\text { Farm animal at } \\
\text { home }\end{array}$ & $0.35(0.04,0.94)$ & $0.39(0.10,1.05)$ & $0.94(0.28,2.30)$ & $0.78(0.19,2.19)$ & $0.88(0.21,2.42)$ & $0.94(0.23,2.66)$ & $1.15(0.58,2.08)$ & $1.03(0.49,1.94)$ \\
\hline \multicolumn{9}{|l|}{ Area of residence } \\
\hline $\begin{array}{l}\text { Sub-rural (Vs } \\
\text { Rural) }\end{array}$ & $1.52(1.05,2.20)$ & $1.64(1.11,2.42)$ & $1.61(0.97,2.71)$ & $1.77(1.02,3.10)$ & $0.99(0.56,1.72)$ & $1.04(0.56,1.88)$ & $0.68(0.47,0.96)$ & $0.75(0.51,1.10)$ \\
\hline Urban (Vs Rural) & $1.37(1.00,1.90)$ & $1.44(1.02,2.05)$ & $1.42(0.91,2.26)$ & $1.46(0.90,2.43)$ & $1.03(0.66,1.65)$ & $1.29(0.80,2.12)$ & $0.89(0.68,1.16)$ & $0.98(0.73,1.33)$ \\
\hline
\end{tabular}

† Adjusted for each other as well as community (G/C and T/C), gender, parents' nationality, parents' level of education, family history of allergies, animals at home, passive smoking, maternal smoking during pregnancy, mode of delivery, birth weight and exclusive breastfeeding duration.

₹ Adjusted for each other as well as community (G/C and T/C), gender, parents' nationality, parents' level of education, family history of allergies, animals at home and passive smoking at home. Bedroom sharing,

nursery attendance, maternal smoking during pregnancy, mode of delivery, birth weight and exclusive breastfeeding duration were not available for the 13-14 year-old children. 
Table 5 Unadjusted and adjusted odds ratios of asthma and allergic symptoms in children aged 7-8 and 13-14 from the Greek-Cypriot and Turkish-Cypriot communities in relation to other risk factors in G/C and T/C children

\begin{tabular}{|c|c|c|c|c|c|c|c|c|}
\hline & \multicolumn{8}{|c|}{ Children $7-8$ years of age } \\
\hline & \multicolumn{2}{|c|}{ Current wheeze } & \multicolumn{2}{|c|}{ Severe asthma } & \multicolumn{2}{|c|}{ Current eczema } & \multicolumn{2}{|c|}{ Current Rhinoconjuctivitis } \\
\hline & $\begin{array}{c}\text { Unadjusted OR } \\
(95 \% \mathrm{Cl})\end{array}$ & $\begin{array}{l}\text { Adjusted ORt } \\
(95 \% \mathrm{Cl})\end{array}$ & $\begin{array}{l}\text { Unadjusted OR } \\
(95 \% \mathrm{Cl})\end{array}$ & $\begin{array}{l}\text { Adjusted ORt } \\
(95 \% \mathrm{Cl})\end{array}$ & $\begin{array}{l}\text { Unadjusted OR } \\
\quad(95 \% \mathrm{Cl})\end{array}$ & $\begin{array}{l}\text { Adjusted ORt } \\
(95 \% \mathrm{Cl})\end{array}$ & $\begin{array}{l}\text { Unadjusted OR } \\
(95 \% \mathrm{Cl})\end{array}$ & $\begin{array}{l}\text { Adjusted ORt } \\
(95 \% \text { Cl) }\end{array}$ \\
\hline \multicolumn{9}{|l|}{ Parental education } \\
\hline Both secondary & $0.77(0.59,1.00)$ & $0.77(0.57,1.02)$ & $0.60(0.40,0.89)$ & $0.67(0.43,1.03)$ & $1.03(0.67,1.59)$ & $0.92(0.58,1.47)$ & $0.44(0.28,0.67)$ & $0.50(0.31,0.79)$ \\
\hline At most one tertiary & $0.70(0.50,0.96)$ & $0.63(0.44,0.90)$ & $0.48(0.27,0.80)$ & $0.45(0.25,0.78)$ & $1.03(0.62,1.70)$ & $0.80(0.46,1.37)$ & $0.71(0.43,1.13)$ & $0.74(0.44,1.22)$ \\
\hline Both tertiary & $1.27(0.93,1.73)$ & $1.13(0.79,1.61)$ & $0.84(0.50,1.37)$ & $0.80(0.45,1.39)$ & $1.55(0.95,2.53)$ & $1.01(0.58,1.76)$ & $0.87(0.53,1.42)$ & $0.86(0.49,1.51)$ \\
\hline Animals at home & $1.15(0.94,1.41)$ & $1.13(0.91,1.40)$ & $1.11(0.81,1.53)$ & $1.09(0.78,1.53)$ & $1.19(0.88,1.60)$ & $1.28(0.93,1.77)$ & $1.05(0.76,1.44)$ & $1.03(0.73,1.44)$ \\
\hline \multicolumn{9}{|l|}{ Smoking at home } \\
\hline Up to $20 \mathrm{cig} /$ day & $1.04(0.83,1.29)$ & $1.11(0.88,1.41)$ & $1.27(0.90,1.78)$ & $1.26(0.87,1.81)$ & $0.88(0.62,1.23)$ & $1.04(0.72,1.49)$ & $1.28(0.90,1.81)$ & $1.38(0.96,2.00)$ \\
\hline$\geq 20 \mathrm{cig} / \mathrm{day}$ & $1.32(1.00,1.74)$ & $1.19(0.87,1.62)$ & $1.71(1.11,2.57)$ & $1.47(0.90,2.32)$ & $1.04(0.66,1.58)$ & $0.95(0.57,1.53)$ & $1.74(1.13,2.63)$ & $1.75(1.09,2.76)$ \\
\hline $\begin{array}{l}\text { Maternal smoking during } \\
\text { pregnancy }\end{array}$ & $1.74(1.26,2.38)$ & $1.55(1.08,2.17)$ & $1.60(0.96,2.52)$ & $1.10(0.63,1.84)$ & $1.74(1.02,2.80)$ & $1.84(1.04,3.11)$ & $1.08(0.60,1.81)$ & $0.78(0.42,1.36)$ \\
\hline \multirow[t]{4}{*}{ Family history } & $2.82(2.30,3.46)$ & $2.78(2.23,3.45)$ & $3.12(2.34,4.41)$ & $3.50(2.51,4.88)$ & $3.64(2.68,4.96)$ & $3.75(2.71,5.22)$ & $3.34(2.43,4.60)$ & $3.65(2.60,5.11)$ \\
\hline & \multicolumn{8}{|c|}{ Children $13-14$ years of age } \\
\hline & \multicolumn{2}{|c|}{ Current wheeze } & \multicolumn{2}{|c|}{ Severe asthma } & \multicolumn{2}{|c|}{ Current eczema } & \multicolumn{2}{|c|}{ Current Rhinoconjuctivitis } \\
\hline & $\begin{array}{l}\text { Unadjusted OR } \\
(95 \% \mathrm{Cl})\end{array}$ & $\begin{array}{l}\text { Adjusted OR } \neq \\
(95 \% \mathrm{CI})\end{array}$ & $\begin{array}{l}\text { Unadjusted OR } \\
(95 \% \mathrm{Cl})\end{array}$ & $\begin{array}{c}\text { Adjusted OR } \neq \\
(95 \% \mathrm{Cl})\end{array}$ & $\begin{array}{l}\text { Unadjusted OR } \\
(95 \% \mathrm{Cl})\end{array}$ & $\begin{array}{l}\text { Adjusted OR } \neq \\
(95 \% \mathrm{Cl})\end{array}$ & $\begin{array}{l}\text { Unadjusted OR } \\
(95 \% \mathrm{Cl})\end{array}$ & $\begin{array}{c}\text { Adjusted OR } \neq \\
(95 \% \text { CI) }\end{array}$ \\
\hline \multicolumn{9}{|l|}{ Parental education } \\
\hline Both secondary & $0.98(0.72,1.34)$ & $1.02(0.73,1.42)$ & $1.03(0.67,1.58)$ & $1.10(0.69,1.76)$ & $0.74(0.48,1.15)$ & $0.83(0.51,1.34)$ & $0.63(0.48,0.84)$ & $0.76(0.56,1.04)$ \\
\hline At most one tertiary & $1.25(0.85,1.82)$ & $1.12(0.73,1.69)$ & $1.30(0.75,2.19)$ & $0.99(0.52,1.81)$ & $0.59(0.31,1.07)$ & $0.58(0.29,1.12)$ & $0.65(0.44,0.94)$ & $0.71(0.46,1.08)$ \\
\hline Both tertiary & $1.11(0.72,1.68)$ & $1.09(0.68,1.72)$ & $1.26(0.69,2.22)$ & $1.24(0.63,2.33)$ & $0.56(0.28,1.07)$ & $0.60(0.27,1.24)$ & $0.69(0.45,1.02)$ & $0.90(0.57,1.40)$ \\
\hline Animals at home & $1.11(0.87,1.41)$ & $1.10(0.85,1.44)$ & $1.14(0.81,1.61)$ & $1.11(0.76,1.63)$ & $2.00(1.36,2.99)$ & $2.35(1.54,3.65)$ & $1.28(1.02,1.62)$ & $1.40(1.08,1.82)$ \\
\hline \multicolumn{9}{|l|}{ Smoking at home } \\
\hline Up to $20 \mathrm{cig} /$ day & $1.33(1.01,1.75)$ & $1.28(0.96,1.71)$ & $1.38(0.94,2.03)$ & $1.36(0.90,2.06)$ & $1.26(0.83,1.93)$ & $1.12(0.72,1.75)$ & $1.44(1.10,1.89)$ & $1.37(1.03,1.83)$ \\
\hline$\geq 20 \mathrm{cig} / \mathrm{day}$ & $1.87(1.28,2.71)$ & $1.57(1.04,2.32)$ & $1.85(1.06,3.10)$ & $1.58(0.87,2.77)$ & $2.35(1.38,3.92)$ & $1.81(1.02,3.13)$ & $2.96(2.11,4.13)$ & $2.73(1.91,3.89)$ \\
\hline Active smoking & $4.88(2.64,8.48)$ & $4.49(2.17,8.64)$ & $5.77(2.63,11.28)$ & $6.03(2.46,13.17)$ & $3.92(1.50,8.51)$ & $2.71(0.78,7.07)$ & $3.20(1.63,5.79)$ & $2.60(1.15,5.27)$ \\
\hline Family history & $3.17(2.40,4.15)$ & $3.25(2.42,4.33)$ & $4.39(3.04,6.30)$ & $5.07(3.43,7.45)$ & $2.19(1.40,3.33)$ & $2.17(1.36,3.37)$ & $2.41(1.82,3.16)$ & $2.26(1.67,3.03)$ \\
\hline
\end{tabular}

† Adjusted for each other as well as community (G/C and T/C), gender, parents' nationality, area of residence, number of siblings, mode of delivery, birth weight, exclusive breastfeeding duration and bedroom sharing. ₹ Adjusted for each other as well as community (G/C and T/C), gender, parents' nationality, area of residence and number of siblings. Maternal smoking during pregnancy, mode of delivery, birth weight and exclusive breastfeeding duration were not available for the 13-14 year-old children. 
Table 6 Adjusted odds ratios of asthma and allergic symptoms in relation to family history of allergies in children from the Greek-Cypriot and Turkish-Cypriot community

\begin{tabular}{|c|c|c|c|c|c|c|}
\hline & \multicolumn{3}{|c|}{ 7-8 year olds } & \multicolumn{3}{|c|}{ 13-14 year olds } \\
\hline & $\mathrm{G} / \mathrm{C}$ & $T / C$ & & $\mathrm{G} / \mathrm{C}$ & $T / C$ & \\
\hline & $\begin{array}{c}\text { Odds ratio } \\
(95 \% \mathrm{Cl})\end{array}$ & $\begin{array}{l}\text { Odds ratio } \\
(95 \% \mathrm{Cl})\end{array}$ & $\begin{array}{l}\text { p-value } \\
\text { LRT§ }\end{array}$ & $\begin{array}{c}\text { Odds ratio } \\
(95 \% \mathrm{Cl})\end{array}$ & $\begin{array}{c}\text { Odds ratio } \\
(95 \% \mathrm{Cl})\end{array}$ & $\begin{array}{c}\text { p-value } \\
\text { LRT§ }\end{array}$ \\
\hline \multicolumn{7}{|l|}{ Outcomes } \\
\hline \multirow[t]{2}{*}{ Current wheeze } & 3.40 & 2.40 & 0.12 & 3.95 & 2.84 & 0.27 \\
\hline & $(2.42,4.77)$ & $(1.80,3.19)$ & & $(2.51,6.21)$ & $(1.92,4.13)$ & \\
\hline \multirow[t]{2}{*}{ Severe asthma } & 5.47 & 2.91 & 0.09 & 5.90 & 4.75 & 0.61 \\
\hline & $(2.87,10.43)$ & $(1.93,4.33)$ & & $(2.92,11.93)$ & $(2.95,7.51)$ & \\
\hline \multirow[t]{2}{*}{ Current eczema } & 3.96 & 3.56 & 0.74 & 1.54 & 2.82 & 0.19 \\
\hline & $(2.48,6.31)$ & $(2.24,5.60)$ & & $(0.76,3.12)$ & $(1.53,4.94)$ & \\
\hline \multirow[t]{2}{*}{ Current rhinoconjuctivitis } & 5.12 & 3.17 & 0.21 & 1.87 & 2.52 & 0.34 \\
\hline & $(2.68,9.79)$ & $(2.11,4.73)$ & & $(1.13,3.07)$ & $(1.73,3.62)$ & \\
\hline
\end{tabular}

† Adjusted for gender, parents' nationality, parents' level of education, area of residence, number of siblings, passive smoking, animals at home, maternal smoking during pregnancy, mode of delivery, birth weight, exclusive breastfeeding duration and bedroom sharing.

F Adjusted for gender, parental nationality, parental level of education, area of residence, number of siblings, passive smoking, and animals at home.

$\S$ Likelihood ratio test comparing models with and without interaction term between community (G/C \& T/C) and family history of allergies.

participation among G/C children. Differential selection bias (whereby allergic G/C children were less likely to participate in the study than $\mathrm{T} / \mathrm{C}$ allergic children) would result in an underestimation of the true prevalence in the G/C community. However, it is more likely that affected children from both communities were probably more likely to have an incentive to participate in the survey. In that case, the lower response among the G/C would have led to an overestimation of the prevalence rates, and hence, differences in the prevalence of symptoms between the two communities may be even larger than those observed.

The fact that the $\mathrm{T} / \mathrm{C}$ community presumably leads a less "westernized" lifestyle than the G/C community, made us speculate that the prevalence of allergies may be lower amongst $\mathrm{T} / \mathrm{C}$ children. Refuting our original hypothesis, our results showed that the prevalence of allergic disorders, with the exception of eczema, was consistently lower in the G/C community, which can not accounted for by the socio-demographic and lifestyle characteristics of the participants.

In contrast, lower prevalence of self-reported family history of allergies was found in the T/C community, suggesting a paradox of a community with lower prevalence of family history of allergy among parents but increased risk of allergies among children. Although such a possibility can not be excluded, it is generally accepted that parental allergy is associated with increased risk of allergies in the offspring $[17,18]$. It is likely that allergic diseases were underdiagnosed among family members of the $\mathrm{T} / \mathrm{C}$ participants. Perhaps, this may be the consequence of lower access of the previous generation of $\mathrm{T} / \mathrm{C}$ to specialized primary care and, as a result, under-detection of allergic diseases or, alternatively, it may be the result of using other diagnostic terms for asthma, eczema or rhinoconjuctivitis in the $\mathrm{T} / \mathrm{C}$ community at the time. Such a possibility can not be ruled out as in a recent national multicenter study for allergic diseases in schoolchildren in Turkey [19] there was a substantial discrepancy in prevalence between lifetime wheezing ( range $31-37,9 \%$ ) and lifetime asthma diagnosed by physician (1.8-6.3\%). Despite the possible misclassification in the $\mathrm{T} / \mathrm{C}$ community, there was no statistical evidence of a weaker association between self-reported family history of allergy and symptoms in the T/C community. We believe that the possible discrepancies in diagnostic labeling between the two communities in Cyprus do not affect the estimates of our study on the prevalence of allergic disorders as we focused on answers to questions of the ISAAC questionnaire referring on symptoms and not on diagnostic labeling.

In contrast to the pattern observed in the case of asthma and hay fever, eczema was more frequent in the G/C community. Although in most European countries high prevalence of eczema is observed along with high prevalence of wheezing $[20,21]$, this is not always the case. In Sweden for instance, the prevalence of reported eczema [20] is considered among the highest in the world $(35,7 \%)$ whereas the prevalence of asthma [21] is rather moderate $(8 \%)$.

Our prevalence estimates are generally within the range observed in other countries of the region such as Greece [15] and Turkey [19] The prevalence of current wheeze in Greece ranged from 5.7\% to $8.7 \%$ in 2001 [15] while in Turkey in 2005 estimates were as high as 14.1\% 
to $22.6 \%$ [19], despite the fact that westernized lifestyle is more prominent in Greece. At least with respects to wheeze, estimates from Turkey appear even higher than the prevalence observed among $\mathrm{T} / \mathrm{C}$ children in our study. The interaction of genetic predisposition with environmental exposures has been shown to influence immune responses relating to asthma pathogenesis and might be of particular importance especially in early life $[22,23]$. Perhaps genetic susceptibility or unknown environmental risk factors underlie the observed difference between the Greek and Turkish populations and might also be responsible for the observed higher prevalence of atopic symptoms in the $\mathrm{T} / \mathrm{C}$ children in our study.

Differences between the younger and older age groups in terms of identified risk factors were mainly observed with regards to (a) the association with number of siblings (i.e. restricted to the younger children), (b) area of residence (with lower prevalence of wheeze in rural areas among older children only) and (c) exposure to tobacco smoke (with higher risk of all study outcomes in older children but only rhinoconjunctivitis).

A higher number of siblings seems to protect the younger children against wheezing and eczema but no similar effect was observed in the older group. In contrast, family size was not associated with the risk for rhinoconjuctivitis in the younger group, but increased the risk by $40 \%$ in the older group. Most epidemiological studies reported an inverse association between number of siblings and eczema, asthma and more consistently with hay fever [24,25]. However, Matheson et al. [26] showed that number of siblings were important predictors only for the development of early onset allergic rhinitis ( $<7$ years of age) but not for later onset allergic rhinitis perhaps explaining the lack of inverse associations in the older children.

Other hygiene hypothesis factors such as early nursery attendance and contact with farm animals at home were not associated with any allergic disorder although the latter could be attributed to the small number of families (260/10156) who kept farm animals at home. Thus, the protective effect for asthma conferred in older children residing in rural areas cannot be attributed to exposure to farm animals but it is more likely reflecting adverse environmental exposures in children residing in urban areas instead, such as high traffic-related emissions, or the generally more westernized lifestyle of the urban population. It is interesting that no similar urban-rural differences were observed in the younger age-group. A recent study by Kolokotroni et al. [12] showed that, at least in $\mathrm{G} / \mathrm{C}$ community, there was an increase in the prevalence of wheeze and hay fever between 2000 and 2008 that occurred primarily in the rural rather than the urban areas. It is possible that environmental and lifestyle changes experienced by both communities in the past decade might have led to increasing "urbanization" of rural areas affecting primarily the younger cohort of children. Similarly, in the case of older children the prevailing environmental and lifestyle factors in the rural areas during the first years of their life might have had a protective effect that is extended until adolescence.

In line with the evidence provided by Bruke et al. [27] in a recent meta-analysis we found strong association of wheeze and maternal smoking during pregnancy in the younger children for whom information was available. Exposure to tobacco smoke at home was also associated with at almost $60 \%$ increase in the risk of wheezing, nearly doubling the risk for eczema and three times for rhinoconjuctivitis, but only among older children. In younger children, the effect was apparent only for rhinoconjunctivitis. A meta-regression study found that older children exposed to second hand tobacco smoke were more likely than younger children to develop asthma, hypothesizing that the risk increases in later childhood as a result of a longer exposure to smoke [28]. Interestingly, after we stratified the analysis by community, we also observed a significant risk of wheezing with passive exposure to tobacco smoke amongst the younger $\mathrm{T} / \mathrm{C}$, but not in the $\mathrm{G} / \mathrm{C}$ children. This finding may reflect a changing pattern in smoking habits at home amongst the younger generation of parents in the $\mathrm{G} / \mathrm{C}$ but not in the $\mathrm{T} / \mathrm{C}$ community (i.e. outdoors instead of indoors).

Active smoking among the 13-14 year olds was not common as it was reported in less than $2 \%$ in both communities. Nevertheless, active smoking in our study was a significant risk factor for wheeze and severity of asthma as well as for rhinoconjuctivitis, even after adjusting for passive household tobacco exposure, consistent with the findings of previous studies [29-31].

Finally, we did not observe any clear socio-economic gradient in allergic symptoms, at least when examining parental education as a surrogate measure of socioeconomic status. Current evidence on the impact of socioeconomic status on development of allergies is rather conflicting [32-36] with some studies indicating a social gradient for allergic disorders in childhood [33,35] and others not [36].

\section{Conclusions}

Allergic disorders are encountered rather commonly in both communities of Cyprus while it seems that, in contrast to our original speculation driven by the hygiene hypothesis, it appears that the higher burden for asthma and rhinoconjuctivitis in the $\mathrm{T} / \mathrm{C}$ children cannot be explained by a less westernized lifestyle. The extent to which genetic susceptibility or other environmental factors, not accounted for in this study, account for the observed differences is not known. 


\section{Abbreviations}

aOR: Adjusted odd ratio(s); Cl: Confidence intervals; G/C: Greek Cypriot; ISAAC: International study of asthma and allergy in childhood;

LRT: Likelihood ratio tests; OR: Odd ratio(s); T/C: Turkish Cypriot.

\section{Competing interests}

All authors declare that they have no competing interest(s) that could interfere with their judgment in analyzing and interpreting the findings of this study.

\section{Authors' contributions}

PY conceived and secured funding for the current study. PY, DM and KA have made contributions to the design of the study. PY supervised and OK coordinated the data collection phase of the study in the $\mathrm{G} / \mathrm{C}$ community and HK supervised and MF coordinated the data collection phase of the study in the T/C community. DL and MF compiled the data. DL performed the statistical analyses. DL and MM wrote the first draft of this paper. NM supervised the statistical analyses, helped drafting and critically revised the manuscript. All authors assisted in the interpretation of results, revised critically and contributed intellectually towards the final version. All authors read and approved the final manuscript.

\section{Acknowledgements}

We wish to acknowledge a) the Cyprus Research Promotion Foundation (grant HEALTH/0506/17) that funded part of the G/C leg of the study and b) United Nations Development Program - UNDP ACT that provided funding for the $T / C$ leg of the study and for a part of the $G / C$ leg of the study. We would also like to acknowledge the field workers for their contribution to the data collection, as well as the headmasters of participating schools, parents and children who took part in the survey.

\section{Author details}

${ }^{1}$ Cyprus International Institute for Environmental \& Public Health in Association with Harvard School of Public Health, Cyprus University of Technology, Limassol, Cyprus. ${ }^{2}$ Department of Nursing, School of Health Sciences, Cyprus University of Technology, Limassol, Cyprus. ${ }^{3} 3 \mathrm{rd}$ Department of Pediatrics, Attikon University Hospital, Athens, Greece. ${ }^{4}$ Cyprus Turkish Medical Association, Nicosia, Cyprus. ${ }^{5}$ Cyprus Social and Economic Research Centre - KADEM, Nicosia, Cyprus. ' Harvard School of Public Health, Boston, Massachusetts, USA. 'University of Maryland School of Public Health, College Park, Maryland, USA.

Received: 11 September 2012 Accepted: 28 May 2013

Published: 16 June 2013

\section{References}

1. The International Study of Asthma and Allergies in Childhood (ISAAC) Steering Committee: Worldwide variation in prevalence of symptoms of asthma, allergic rhinoconjunctivitis, and atopic eczema: ISAAC. Lancet 1998, 351(9111):1225-1232.

2. Asher MI, Montefort S, Björkstén B, Lai CK, Strachan DP, Weiland SK, Williams H, ISAAC Phase Three Study Group: Worldwide time trends in the prevalence of symptoms of asthma, allergic rhinoconjunctivitis, and eczema in childhood: ISAAC Phases One and Three repeat multicountry cross-sectional surveys. Lancet 2006, 368(9537):733-743.

3. Pearce N, Aït-Khaled N, Beasley R, Mallol J, Keil U, Mitchell E, Robertson C, ISAAC Phase Three Study Group: Worldwide trends in the prevalence of asthma symptoms: phase III of the international study of asthma and allergies in childhood (ISAAC). Thorax 2007, 62:758-766.

4. von Mutius E: Allergies, infections and the hygiene hypothesis - The epidemiological evidence. Immunobiology 2007, 212:433-439.

5. Asher Ml: Recent perspectives on global epidemiology of asthma in childhood. Allergol Immunopathol(Madr) 2010, 38:83-87.

6. Wang HY, Wong GW, Chen YZ, Ferguson AC, Greene JM, Ma Y, Zhong NS, Lai CK: Prevalence of asthma among Chinese adolescents living in Canada and in China. CMAJ 2008, 179:1133-1142.

7. Brugge D, Lee AC, Woodin M, Rioux C: Native and foreign born as predictors of pediatric asthma in an Asian immigrant population: a cross sectional survey. Environ Health 2007, 6:13.

8. Subramanian SV, Jun HJ, Kawachi I, Wright RJ: Contribution of race/ ethnicity and country of origin to variations in lifetime reported asthma: evidence for a nativity advantage. Am J Public Health 2009, 99:690-697.

9. Wichmann HE: Possible explanation for the different trends of asthma and allergy in East and West Germany. Clin Exp Allergy 1996, 26:621-623.

10. von Mutius E, Martinez FD, Fritzsch C, Nicolai T, Roell G, Thiemann HH: Prevalence of asthma and atopy in two areas of West and East Germany. Am J Respir Crit Care Med 1994, 149:358-364.

11. Heinrich J, Hoelscher B, Frye C, Meyer I, Wist M, Wichmann HE: Trends in prevalence of atopic diseases and allergic sensitization in children in Eastern Germany. Eur Respir J 2002, 19:1040-1046.

12. Kolokotroni O, Middleton N, Nicolaou N, Pipis S, Priftis KN, Milton DK, Yiallouros PK: Temporal changes in the prevalence of childhood asthma and allergies in urban and rural areas of Cyprus: results from two cross sectional studies. BMC Publ Health 2011, 11:858.

13. Kalayci O, Saraçlar Y, Sekerel BE, Adalioğlu G, Kuyucu S, Ergör G, Bozer HK, Tuncer A: Prevalence of asthma symptoms among Turkish Cypriot schoolchildren. Turk J Pediatr 1999, 41:413-420.

14. Priftis KN, Panagiotiakos DB, Anthracopoulos MB, Papadimitriou A, Nicolaidou P: Aims, methods and preliminary findings of the physical activity and allergies in children examined in Athens (PANACEA) epidemiological study. BMC Publ Health 2007, 7:140-146.

15. Papadopoulou A, Hatziagorou E, Matziou VN, Grigoropoulou DD, Panagiotakos DB, Tsanakas JN, Gratziou C, Priftis KN: Comparison in asthma and allergy prevalence in the two major cities in Greece: the ISAAC phase II survey. Allergol Immunopathol (Madr) 2011, 39:347-355.

16. Kuyucu S, Saraçlar Y, Tuncer A, Geyik PÖ, Adalıoglu G, Akpınarlı A, Sekerel BE, Sumbuloglu V: Epidemiologic characteristics of rhinitis in Turkish children: the international study of asthma and allergies in childhood (ISAAC) phase 2. Pediatr Allergy Immunol 2006, 17:269-277.

17. Bjerg A, Hedman L, Perzanowski MS, Platts-Mills T, Lundbäck B, Rönmark E: Family history of asthma and atopy: in-depth analyses of the impact on asthma and wheeze in 7- to 8-year-old children. Pediatrics 2007, 120:741-748.

18. Burke W, Fesinmeyer M, Reed K, Hampson L, Carlsten C: Family history as a predictor of asthma risk. Am J Prev Med 2003, 24:160-169.

19. Civelek E, Cakir B, Boz AB, Yuksel H, Orhan F, Uner A, Sekerel BE: Extent and burden of allergic diseases in elementary schoolchildren: a national multicenter study. J Investig Allergol Clin Immunol 2010, 20:280-288.

20. Williams H, Robertson C, Stewart A, Aït-Khaled N, Anabwani G, Anderson R, Asher I, Beasley R, Björkstén B, Burr M, Clayton T, Crane J, Ellwood P, Keil U, Lai C, Mallol J, Martinez F, Mitchell E, Montefort S, Pearce N, Shah J, Sibbald B, Strachan D, von Mutius E, Weiland SK: Worldwide variations in the prevalence of symptoms of atopic eczema in the international study of asthma and allergies in childhood. J Allergy Clin Immunol 1999, 103:125-138.

21. ISAAC Steering Committee: Worldwide variations in the prevalence of asthma symptoms: the international study of asthma and allergies in childhood (ISAAC). Eur Respir J 1998, 12:315-335.

22. Prescott SL, Macaubas C, Smallacombe T, Holt BJ, Holt PG: Development of allergen specific T-cell memory in atopic and normal children. Lancet 1999, 353:196-200.

23. Hoffjan S, Nicolae D, Ostrovnaya I, et al: Gene-environment interaction effects on the development of immune responses in the 1st year of life. Am J Hum Genet 2006, 76:696-704.

24. Kinra S, Davey Smith G, Jeffreys M, Gunnell D, Galobardes B, McCarron P: Association between sibship size and allergic diseases in the Glasgow Alumni Study. Thorax 2006, 61:48-53.

25. Karmaus W, Botezan CJ: Does a higher number of siblings protect against the development of allergy and asthma? A review. J Epidemiol Community Health 2002, 56:209-217.

26. Matheson $\mathrm{MC}$, Walters $\mathrm{EH}$, Simpson JA, Wharton $\mathrm{CL}$, Ponsonby $\mathrm{AL}$, Johns DP, Jenkins MA, Giles GG, Hopper JL, Abramson MJ, Dharmage SC: Relevance of the hygiene hypothesis to early vs. late onset allergic rhinitis. Clin Exp Allergy 2009, 39:370-378.

27. Burke H, Leonardi-Bee J, Hashim A, Pine-Abata H, Chen Y, Cook DG, Britton JR, McKeever TM: Prenatal and passive smoke exposure and incidence of asthma and wheeze: systematic review and meta-analysis. Pediatrics 2012, 129:735-744.

28. Vork KL, Broadwin RL, Blaisdell RJ: Developing asthma in childhood from exposure to secondhand tobacco smoke: insights from a meta-regression. Environ Health Perspect 2007, 115:1394-1400. 
29. Gilliland FD, Islam T, Berhane K, Gauderman WJ, McConnell R, Avol E,

Peters JM: Regular smoking and asthma incidence in adolescents. Am J Respir Crit Care Med 2006, 174:1094-1100.

30. Genuneit J, Weinmayr G, Radon K, Dressel H, Windstetter D, Rzehak P, Vogelberg C, Leupold W, Nowak D, von Mutius E, Weiland SK: Smoking and the incidence of asthma during adolescence: results of a large cohort study in Germany. Thorax 2006, 61:572-578.

31. Gómez M, Vollmer WM, Caceres ME, Jossen R, Baena-Cagnani CE: Adolescent smokers are at greater risk for current asthma and rhinitis. Int J Tuberc Lung Dis 2009, 3:1023-1028.

32. Rona RJ: Asthma and poverty. Thorax 2000, 55:239-244.

33. Heinrich J, Popescu MA, Wjst M, Goldstein IF, Wichmann HE: Atopy in children and parental social class. Am J Public Health 1998, 88:1319-1324.

34. Forastiere F, Agabiti N, Corbo GM, Dell'Orco V, Porta D, Pistelli R, Levenstein S, Perucci CA: Socioeconomic status, number of siblings, and respiratory infections in early life as determinants of atopy in children. Epidemiology 1997, 8:566-570

35. Mielck A, Reitmeir $P$, Wjst M: Severity of childhood asthma by socioeconomic status. Int J Epidemiol 1996, 25:388-393.

36. Hancox RJ, Milne BJ, Taylor DR, Greene JM, Cowan JO, Flannery EM, Herbison GP, McLachlan CR, Poulton R, Sears MR: Relationship between socioeconomic status and asthma: a longitudinal cohort study. Thorax 2004, 59:376-380

doi:10.1186/1471-2458-13-585

Cite this article as: Lamnisos et al:: Prevalence of asthma and allergies in children from the Greek-Cypriot and Turkish-Cypriot communities in Cyprus: a bi-communal cross-sectional study. BMC Public Health 2013 13:585.

\section{Submit your next manuscript to BioMed Central and take full advantage of:}

- Convenient online submission

- Thorough peer review

- No space constraints or color figure charges

- Immediate publication on acceptance

- Inclusion in PubMed, CAS, Scopus and Google Scholar

- Research which is freely available for redistribution 